\title{
Akıllı Kampüs Teknolojileri ve Uygulamaları Üzerine Bir Araştırma
}

\author{
Gamze ALTUN ${ }^{1 *}$, Murat ZENCIRKIRAN ${ }^{1}$
}

Öz

Yarattığı dijital ortamlar sayesinde insanların ve teknolojik sistemlerin birbiri ile sürekli etkileşim halinde olmasını sağlayan akıllı bir kampüsün tam olarak nasıl şekil alması gerektiğine ve akıllı kampüsü oluşturan ana bileşenlerin neler olduğuna dair net bir algının henüz oluşmamış olduğu ve konu ile ilgili literatürde yetersizlikler bulunduğu dikkat çekmektedir. Bu nedenle, bu araştırmanın amacı, akıllı kampüs algısına bir netlik kazandırmak, Türkiye'deki ve Dünya'daki örnek uygulamaları inceleyerek akıllı kampüs kriterlerini ortaya koymak, akıllı bir kampüse ait karar türlerine ilişkin kapsamlı bir kaynak oluşturarak kavramsal belirsizliği ortadan kaldırmak, üniversite kampüslerinin nasıl değişmekte olduğunu ve nasıl değişmesi gerektiğini yorumlamak ve paydaşların çalışmalarına fayda sağlamaktır. Bu çalışma konu ile ilgili detaylı bir literatür taramasına dayalı olup öncelikle "akıllı (smart)" kavramı, akıllı kentin kavramsal çerçevesi; ardından akıllı kentlerin bileşenleri ele alınmıştır. Daha sonra ise akılıı kentlerin küçük ölçekte iyi bir yansıması olan akıllı kampüslerin özellikleri, bileşenleri, teknolojileri ve bazı akıllı kampüs örnekleri incelenmiştir. İncelemeler göstermiştir ki; kampüsün var olan potansiyelini teknoloji, inovasyon ve yaratıcılık dâhilinde geliştiren, bu sayede kampüsün aksayan yönlerine hızlı ve etkin çözümler sunabilen; sürdürülebilir, bütüncül ve çok yönlü akıllı kampüs uygulamalarının ülkemizde yaygınlaştırılması gerekmektedir.

Anahtar Kelimeler: Akılı (Smart), Akılı Kent, Akıllı Kampüs, Teknoloji.

\section{A Research on Smart Campus Technologies and Applications}

\begin{abstract}
\footnotetext{
${ }^{1}$ Bursa Uludağ Üniversitesi, Ziraat Fakültesi, Peyzaj Mimarlığı Bölümü, Bursa

* İlgili yazar/Corresponding author: gamzealtun@uludag.edu.tr

Gönderim Tarihi / Received Date: 30.12 .2020

Kabul Tarihi / Accepted Date: 03.08.2021
}

It is seen that a clear perception of exactly how a smart campus should take shape or what the main components that can create a smart campus are, has not yet been formed, and it is noteworthy that there are inadequacies in the related literature. Therefore, this research aims to bring clarity to the smart campus perception, examining practices in Turkey and World reveals smart campuses criteria, creating a comprehensive resource regarding the types of decisions of a smart campus to eliminate the conceptual ambiguity, to interpret how university campuses are changing and how they should change and to benefit the work of stakeholders. The study is based on a detailed literature review on this subject, primarily the concept of "smart", the conceptual framework of the smart city; Then, the components of smart cities are discussed, and then the features, components, technologies and some examples of smart campuses, which are a good reflection of smart cities on a small scale, are examined. Investigations have shown that developing the existing potential of the campus within technology, innovation, and creativity, in this way providing fast and 
effective solutions to the problems of the campus; sustainable, holistic and versatile smart campus applications need to be popularized in our country.

Keywords: Smart, Smart City, Smart Campus, Technology.

\section{Giriş}

Hızla gelişen teknoloji, insanların yaşam tarzlarında, öğrenme yöntemlerinde ve çalışma alışkanlıklarında büyük dönüşümler yaratmaktadır (Dong ve diğ., 2020, s. 1; Liu ve diğ., 2017). Teknolojinin gelişmesine bağlı olarak öğrenme yöntemlerinin ve ortamlarının kademeli olarak değişmesi ve kişiselleştirilmiş öğrenmeye yönelik artan talep, eğitim alanında reform ve gelişimi zorunlu kılmakta ve akıllı bir eğitim sisteminin üst düzey biçimi olduğu düşünülen akıllı kampüsler dünya üzerinde giderek daha fazla ilgi görür hale gelmektedir (Dong ve diğ., 2020, s. 1).

Vatandaşları akıllı iş gücüne dönüştüren akıllı bir öğrenme ortamı sağlaması akıllı kampüsleri akıllı kent çerçevesinin ayrılmaz bir parçası haline getiren bir diğer önemli noktadır. Eğitim akıllı kentlerin önemli bir bileşenidir ve performans değerlendirmelerinde önemli kriterlerden biri olarak görülmektedir (Dong ve diğ., 2020, s. 1; Liu ve diğ., 2017; Kwok, 2015, s. 2). Akıllı vatandaş kavramı, akıllı öğrenme ortamlarına yönlendirmekte bu ise gerçek anlamda başarıya ulaşabilmiş akıllı kentlerin meydana getirilebilmesi için akıllı insan boyutunun üzerinde durulması gerekliliğinin neredeyse zorunlu olduğunu göstermektedir (Sadioğlu ve Dinç, 2020, s. 193).

Bu doğrultuda çalışmamız kapsamında, akıllı insan boyutunun geliştirilebileceği uygun ortamlar olduğu düşünülen, kentlere göre daha küçük ölçekli yerleşim birimleri olan üniversite kampüslerinin akıllı planlanmasına dair soru işaretlerinin ortadan kaldırılması hedeflenmiş olup öncelikle "akıllı (smart)" ve "akıllı kent" kavramları açıklığa kavuşturulmaya çalışılmıştır. Bu amaç doğrultusunda çalışmamızda sırasıyla; "akıllı (smart)" kavramı, akılı kentin kavramsal çerçevesi ile akıllı kentlerin bileşenleri ele alınacak olup akıllı kentlerin küçük ölçekte iyi bir yansıması olan akıllı kampüslerin özellikleri, bileşenleri, teknolojileri ve bazı akıllı kampüs örnekleri incelenecektir.

\section{Akıllı (Smart) ve Akıllı Kent Kavramları}

"Akıllı" kelimesi, genellikle bir nesnenin kendisine yerleştirilmiş olan zekâyı sunma kabiliyetini tanımlamak için kullanılmaktadır. Nispeten yeni bir kavram olan "Akıllı Konsept" büyümeye devam etmekte ve sadece tek bir nesneyle (akıllı telefon vb. gibi) sınırlı kalmayıp aynı zamanda akıllı kent, akıllı kampüs, akıllı şebeke vb. gibi insan yaşamının daha geniş yönlerini de kapsamaktadır (Muhamad ve diğ., 2017, s. 384). Kentsel süreçleri iyileştirmek, planlama stratejileri geliştirmek ve yeni çözümleri koordineli ve bütünsel bir şekilde uygulamak için çeşitli akıllı planlama metodolojileri önerilmektedir (Pagliaro ve diğ., 2016, s. 1). Bu entegre planlama, "akıllı (smart)" konseptinin özüdür ve farklı ölçeklerde uygulanabilmektedir.

Kent, sürekli toplumsal gelişme içinde olan ve toplumun, yerleşme, barınma, ulaşım, çalışma dinlenme, eğlenme gibi intiyaçlarının karşılandığı küçük komşuluk birimlerinden oluşan yerleşme birimidir (Keleş, 1998). Sanayi devrimi ile birlikte, kentlerin insan hayatındaki yeri ve bir yerleşim yeri olarak önemi giderek artmıştır. Bugün Dünya nüfusunun \%55'i kentlerde yaşamaktadır ve bu oranın 2050 yılına kadar \%68'e çıkması beklenmektedir (URL-1). 2030 yılına kadar her on kişiden altısının bir kentte yaşıyor olması ve 2050'ye kadar bu rakamın yedi kişiye kadar çıkması beklenmektedir. Bu rakamlar kentte yaşayan nüfus sayısının her yıl yaklaşık 60 milyon 
artacağını göstermektedir (European Parliament, 2014, s. 17). Ülkemizde kentleşme hareketlerinin gelişimi incelendiğinde ise 1950'ye kadar oldukça yavaş artış gösteren ülke kent nüfusunun, 1950'den sonra kaynağını kırsal alanın itici faktörlerinden ve kentlerin çekim özelliklerinden alarak çok hızlı bir artış sürecine girdiği görülmektedir (Işık, 2005, s. 58).

Günümüzde kentleşme hızı büyük bir ivmeyle artış gösterirken kentlerin güvenlik, ulaşım, barınma ve enerji konularında sahip oldukları sınırlı kaynakları daha aktif ve randımanlı kullanabileceği metotlara intiyacı da aynı oranda artmaktadır. Bu durum şehirlerin değişmesi ve gelişmesi gerekliliğini ortaya koyarken (Herzberg, 2017, s. 13) planlama, tasarım, finans, kentsel altyapı, hizmetlerin işletilmesi ve yönetişimi konularında yeni bakış açılarının doğmasını da tetiklemektedir (Örselli ve Akbay, 2019, s. 229; Harrison ve Donnelly, 2011, s. 1). Bütün bu ihtiyaçlar neticesinde yüksek yaşam kalitesini daha düşük maliyetle, sağlıklı ve verimli altyapısal hizmetlerle sunabilmek için, kent merkezi ve yerel yönetişimlerin bilgi ve iletişim teknolojilerini kullanmaları gerekli bir hal almaktadır (Mirghaemi, 2019, s. 39). Akıllı Şehirler ve Topluluklar Avrupa Yenilikçilik Ortaklığının (EIP-SCC) hazırladığı Stratejik Uygulama Planı'nda içinde bulunduğumuz; Birleşmiş Milletler 2016 Dünya Kentleşme Beklentileri Raporu'nda "Tarihin En Çarpıcı Kentsel Büyüme Dönemi" olarak adlandırılan dönemde değişimin akıllıca planlanması ve şehirlerimizin "Akıllı Kentlere" dönüştürülmesi gerekliliğinin altı çizilmektedir (Herzberg, 2017, s. 7).

Akıllı kent kavramı itibarlı ve cazip olmakla birlikte, konuyu farklı açılardan ifade eden, Zeki Kent (Intelligent City), Bilgi Kenti (Knowledge City), Sürdürülebilir Kent (Sustainable City), Yetenekli Kent (Talented City), Kablolu Kent (Wired City), Dijital Kent (Digital City), Eko-kent (Ecocity) gibi kavramlar da mevcuttur (European Parliament, 2014, s. 22).

Hakkında henüz ortak tek bir tanımlama olmamasına rağmen odağına insanı alarak kentin temelden en üst aşamaya tüm ihtiyaçlarını bilgi ve teknoloji odaklı çözümlerle ele alan akıllı kent (Herzberg, 2017, s. 7) tanımının genel olarak şehirlerin çözüm aranan sorunlarına ve temel ihtiyaçlarına göre şekillendiği tespit edilmiştir (URL-2).

Avrupa parlamentosu (2014)'nun tanımına göre akıllı kent; çok paydaşlı, belediye odaklı ortaklık temelinde bilgi ve iletişim teknolojileri tabanlı çözümler ile kamu sorunlarını çözme anlayışını benimseyen kenttir. Ulusal Akıllı Şehirler Stratejisi ve Eylem Planı'nda ise akıllı kentler, paydaşlar arası iş birliği ile hayata geçirilen, yeni teknolojileri ve yenilikçi yaklaşımları kullanan, verilere ve uzmanlığa dayalı olarak gerekçelendirilen ve bununla birlikte gelecekteki problem ve intiyaçları ön görerek hayata değer katan çözümler sağlayan, daha yaşanabilir ve sürdürülebilir kentler olarak tanımlanmıştır (URL-3). Bu tanımlamalara göre akılı kentler, içerisinde yalnızca ileri teknolojilerin barındığı bir yer değil, aynı zamanda kentli insanların ve oluşturdukları büyük toplulukların intiyaçlarını ve beklentilerini karşılayabilen şehirler anlamına gelmektedir (Albino ve diğ., 2015; Mirghaemi, 2019, s. 39).

\subsection{Akıllı kent bileşenleri}

Farklı akıllı kent tanımları olduğu gibi akıllı kentler ile ilgili olarak farklı yaklaşımlar da bulunmaktadır. Bu yaklaşımlar akıllı ekonomi, akıllı vatandaş, akıllı yönetişim, akıllı yaşam, akıllı hareketlilik ve akıllı çevre olmak üzere 6 ana başlık altında sınıflandırılmaktadır (Şekil 1) (URL-2). 


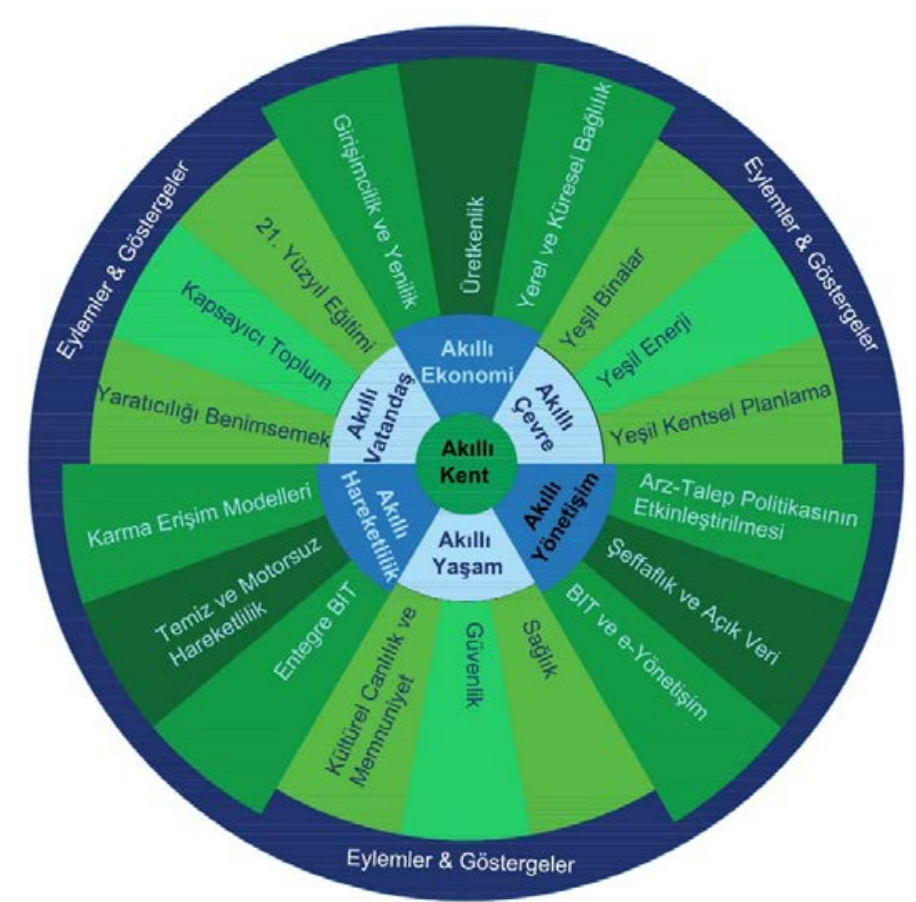

Şekil 1. Boyd Cohen (2018) Akıllı Şehir Çarkı(Yazar tarafından çevrilmiştir.)

\subsubsection{Akıllı vatandaş}

Yaşam boyu öğrenmeye eğilimli, sosyal ve kültürel çoğulculuğu esas alan; esnek, yaratıcı, açık görüşlü ve kamusal hayata katılımı destekleyen bireyleri ifade etmektedir (Nam ve Pardo, 2011, s. 287). Akıllı kent uygulamalarında akıllı insan veya akıllı vatandaş kavramının odak noktası olduğu ve akıllı vatandaş olmadan akılı kentlerin başarıya ulaşamayacağı da unutulmamalıdır (Örselli ve diğ., 2018, s. 8).

\subsubsection{Akıllı yönetişim}

Kamusal, özel ve sivil paydaşları kentsel yönetimle ilgili hizmet alanlarında etkin, etkili ve verimli kılan ve paydaşlar arasındaki iletişimi ve işbirliğini bilgi ve iletişim teknolojileri yardımıyla sağlayan yönetişim şeklidir (Gürsoy, 2019, s. 60).

\subsubsection{Akıllı ekonomi}

Geleneksel üretim ve iş yapma yöntemlerinin değiştirilerek e-iş ve e-ticaret kavramlarının günlük hayatın bir parçası haline getirilmesi ile malların, hizmetlerin ve bilginin sanal ortamda hızlı ve etkin bir şekilde dolaşımının sağlanmasıdır. Buna paralel olarak girişimciliğin, istihdamın ve verimliliğin desteklenmesini hedefleyen bilgi ve iletişim teknolojileri temelli üretim ve hizmet sunumunun bir ifadesidir (Gürsoy, 2019, s. 61).

\subsubsection{Akıllı hareketlilik}

Bilgi ve iletişim teknolojileri destekli ulaşım, nakliye ve lojistik hizmetlerini içeren akıllı mobilite (hareketlilik) kentlerde yaşanan aksaklıkları en az seviyeye indirmeyi, vatandaşların yaşam kalitesini yükseltmeyi ve kentlerin sürdürülebilirliğini sağlamayı hedeflemektedir (Bilici ve Babahanoğlu, 2018, s. 131; Cledou ve diğ., 2018, s. 1).

\subsubsection{Akıllı çevre}

Bilgi ve iletişim teknolojileri desteği ile sürdürülebilirliğinin sağlanabilmesi, yeşil alanlar ve su kaynaklarının kontrol edilebilmesidir. Yenilenebilir enerji, sürdürülebilir kaynak yönetimi, akıllı enerji şebekeleri, mikro şebekeler, akıllı sayaçlar, ileri hava kirliliği 
izleme sistemleri, çevre dostu yeşil binalar, yeşil şehir planlaması, enerji verimli akıllı sokak aydınlatmaları, katı atık yönetimi, akıllı su yönetim ve drenaj gibi sistemleri kapsamaktadır (URL-4).

\subsubsection{Akıllı yaşam}

Bu kavram toplumun esas gereksinimlerine akıllı bir yaklaşımla çözümler üreterek yaşam kalitesini artırmayı amaçlayan, bilgi ve iletişim teknolojilerinden yararlanan yaşam tarzlarını, davranış ve tüketim alışkanlıklarını ifade etmektedir (Akbaş, 2018, s. 144).

Dünya genelinde kentlerin birçoğu akıllı kent olma yolunda ciddi adımlar atmakta ve çalışmalar yapmakta olsalar da günümüzde hiçbir şehir $\% 100$ akıllı kent olarak nitelendirilebilecek bir seviyede değildir. Bir akıllı kentin listelenen altı unsurun her birisinde yetkin ve tatmin edici seviyede olması gerekmekle bu unsurların nispi önemleri şehirlerin intiyaç ve isteklerine göre değişiklik gösterebilmektedir. Yani akıllı kent kavramının uygulanması; her kentin kendine özgü politikalarına, amaçlarına, finansman sağlamasına ve kapsamına göre çeşitlenmektedir (Mirghaemi, 2019, s. 40; Sadioğlu ve Dinç, 2020, s. 193).

Verimlilik üzerindeki odaklanma, toplumsal bağlar ve yaşam kalitesi gibi toplumsal değerlerin sınırlandırılmasına yol açacağı için yeni kent planlamalarında "sürdürülebilirlik" boyutunun tartışımasına yol açmaktadır (Akbaş, 2018, s. 141; Bria, 2012). Bu doğrultuda teknolojik çözümlerin planlanmadan çoğaltılması çeşitli riskleri beraberinde getirebilir ve aynı çözüm yöntemleri tüm kentler için uygun olmayabilir (Kitchin, 2015, s. 132) Böylesi sorunların meydana gelmemesi adına akıllı kent için uygun herhangi bir model, toplumun akıllılığı, toplum refahı ve yaşam kalitesi üzerine odaklanmalıdır (Susanti ve diğ., 2016, s. 197).

\section{Akıllı Kent ve Akılı Kampüs Arasındaki İlişki}

Üniversiteler ve kentler, çevresel etki, yönetim ve organizasyon sorunları, iç ve dış hareketlilik, altyapı yetersizliği, düşük verimlilik, temel hizmetlerin ve özelliklerin eksikliği buna bağlı olarak kullanıcıların memnuniyetsizliği gibi benzer sorunlar ve zorluklara sahiptir (Pagliaro, 2016, s. 1). Boyut ve yapı türlerinde farklılıklar görülse de, üniversite kampüsleri birkaç dönümlük arazileri işgal eden ofis binaları, amfiler, kütüphaneler, uygulama sahaları, satış alanları, otoparklar ve toplu taşıma durakları gibi çeşitli alanlar ve tesisleri içermeleri, işlevlerin ve kullanıcıların çokluğu, etkinlikler ve bağlantılar gibi çeşitli açılardan küçük, bağımsız birer kent niteliğindedirler (Pagliaro ve diğ., 2016, s. 2; Torres-Sospedra ve diğ., 2015; Sutjarittham ve diğ., 2018, s. 1). On binlerce insanla dolu bu mini kentler, öğrenciler ve akademisyenlerden personele ve genel ziyaretçilere kadar her biri farklı intiyaçlara ve profile sahip dinamik bir insan akışına ev sahipliği yaparken, altyapı gibi somut veya sosyal ilişkiler ve inovasyon gibi soyut konularda, bulundukları şehirlerle etkileşim halindedir ve tıpkı kentler gibi paydaşlara daha iyi hizmetler sunmak için sürekli baskı altındadırlar (Villegas-Ch ve diğ., 2019, s. 1; Sutjarittham ve diğ., 2018, s. 1).

Dünya çapında birçok kent, vatandaşlarının yaşam kalitesini ve refahını iyileştirmenin yanı sıra enerji verimliliğini artırmak, yönetişimlerini iyileştirmek ve karbon emisyonlarını azaltmak için akıllı kent konseptini benimsemektedir (Fortes ve diğ., 2019, s. 2). Üniversite kampüsleri ise küçük bir kent niteliği taşımasının yanı sıra güvenli internet, uzaktan eğitim, e-devlet, görüntülü haberleşme, çevrimiçi ödeme sistemleri, sosyal medya kullanımı ve teknolojik donanım gibi konulara ihtiyaç duyan, yenilikleri benimsemeye ve teşvik etmeye istekli geniş bir öğrenci, akademik personel 
ve çalışan topluluğunu birleştiren bir nüfusa sahip olması ile bu yaklaşımı güçlendirmekte hem de akıllı kent girişimlerinin uygulanması ve ilerletilmesi için uygun bir ortam sağlamaktadır (Fortes ve diğ., 2019, s. 2; Gürsoy ve Ömürgönülşelen, 2019, s. 22).

Akıllı kentlerin bileşenlerini akıllı ekonomi, akıllı insanlar, akıllı yönetişim, akıllı hareketlilik, akıllı çevre ve akıllı yaşam biçiminde sınıflandıran Lombardi ve diğ., (2012), akıllı insanlar için kent yaşamının önemli yönünü eğitim olarak belirtmiştir. Akıllı kentlerdeki kampüs, kütüphane vb. öğrenme çevreleri, vatandaşların akıllı öğrenmelerini desteklemektedir. Akıllı kent yatırımları çerçevesinde insan unsuru, öğrenme araçları, öğrenme süreçleri, öğrenme merkezleri gibi öğelerin entegre edilmesi yatırımların atıl ve israfa sebep olacak girişimlere dönüşmemesi için önemlidir (Sadioğlu ve Dinç, 2020, s. 194). Bu bağlamda akıllı kent yaklaşımının üniversite alanlarına uygulanması ile ortaya çıkan "Akıllı Kampüslerin" akıllı insan topluluğunu destekleyerek kent için büyük avantajlar sağlayabileceği düşünülmektedir.

\section{Akıllı Kampüs}

Teknolojide yaşanan hızlı gelişmeler yakın geleceğe yön vermekte ve nesnelerle insan etkileşimi üzerinde yeni paradigmalar yaratmaktadır. Buna bağlı olarak sosyal ortamlardaki teknolojiler ve uygulamalar arasındaki entegrasyon ise çevredeki süreçlerin otomasyonunu, uzaktan kumandayı ve karar vermeyi destekleyen akıllı ortamların oluşumunu teşvik etmektedir (Villegas-Ch ve diğ., 2019, s. 4).

Hızlı kentleşme, zorlayıcı kentsel problemler ve kentsel sürdürülebilirliğe yönelik dramatik tehditler nedeniyle literatürde "akıllı kent"' kavramına dair çalışmalar ivme kazanırken (Dameri ve Cocchia, 2013; Gil-Garcia ve diğ., 2015, s. 62; Vasileva ve diğ., 2018, s. 2), literatürde 2000'li yılların başından beri yer almakta olan "akıllı kampüs" kavramının kapsamlı bir şekilde çalışılmadığı dikkat çekmektedir. Buna ek olarak akıllı kampüs terimine ait araştırmaların parçalı ve büyük ölçüde merkezine akıllı insan kavramını alan belirli dijital teknolojilere odaklanmakta olduğu görülmektedir (Vasileva ve diğ., 2018, s. 2).

Geleneksel kampüsler, eğitim kurumlarının, kütüphaneler, derslikler, yurtlar, öğrenci merkezleri, yemekhaneler ve rekreasyon alanları olarak inşa edildiği birer arazi parçaları iken (Jenal ve diğ., 2016, s. 2) yeni nesil kampüsler geçmişin ve çoğu açıdan ise günümüzün kolejlerinden ve üniversitelerinden farklı bir görünümdedir. Teknoloji söz konusu olduğunda, günümüzün üniversite öğrencileri ve öğretim üyeleri, eğitim gördükleri ve çalıştıkları kampüslerden daha hızlı akıllı çözümler beklemektedirler. Dijital olarak bağlı bir topluluk tarafından yönlendirilen temassız ve sezgisel deneyimler sağlayan teknolojileri kullanan akıllı kampüsler, öğrencinin ve öğretim üyelerinin beklediği hizmet düzeyini sağlamak için gerçek dönüşümü sağlamayı hedeflemektedir (URL-5).

Yönetim, öğretim, bilimsel araştırma ve kampüs yaşam birliği için uygun olan her türlü uygulama ve hizmet sistemini entegre etmesi ve BiT'e (Bilgi ve İletişim Teknolojileri) dayalı akıllı bir öğretim, öğrenim ve yaşam oluşturmayı ifade etmesi gibi nedenlerle (Du ve diğ., 2016, s. 714) akıllı kampüslerin, kampüs çevresinde silolar halinde kurulan bir sistem, uygulama veya altyapı koleksiyonundan daha fazlası olduğu söylenebilir (URL5). Üniversite nüfusu ile çevresi arasında daha iyi bir birliktelik sağlayan ve herkes için yeni bir deneyim yaratan stratejik çerçevelere sahip akıllı kampüsler, sahip oldukları kaynakları verimli bir şekilde yönetmek, çevresel etkileri azaltmak ve öğrencilere öğrenme ortamları sunmak için çeşitli teknolojileri birleştirmektedir (URL-5; Villegas-Ch 
ve diğ., 2019, s. 4). Akıllı kampüs uygulamalarının temeli olan kampüs teknolojik altyapısının geliştirilmesi ile oluşturulmuş teknolojik öğrenme ortamları (Özcan ve diğ., 2017), öğrencilerin yenilikçi bir şekilde öğrenmelerine ve düşünmelerine imkan tanır ve bir organizasyondaki öğretimin ve öğrenme becerilerinin gelişimini sağlar. Bu fayda, öğrencileri yeni becerileri tecrübe edilmemiş yollarla edinmeye, en yeni teknolojileri deneyimleyemeye, 7/24 izleme ve enerji yönetimlerini verimli bir şekilde öğrenmeye motive etmeye odaklanmaktadır (Subbarao ve diğ., 2019).

\subsection{Akıllı kampüs uygulamalarını destekleyen teknolojiler}

Teknolojideki yenilikler akıllı kampüs gelişimini tetikleyen en büyük unsurdur. Literatürde, akıllı kampüs uygulamalarını destekleyen ana teknolojiler arasında bulut bilişim, nesnelerin interneti (IOT), artırılmış gerçeklik (AR) ve yapay zekâ (AI) yer almaktadır (Şekil 2) (Köseoğlu ve Demirci, 2018, s. 41). Bahsi geçen teknolojilerin nitelikleri ve akıllı kampüslere olan faydaları bu bölümde gözden geçirilmektedir.

\subsubsection{Nesnelerin interneti}

Kapsamlı bir ağ üzerine inşa edilmiş bilgi teknolojisine dayanan yeni bir kavram olan "Nesnelerin İnterneti" kavramı, akla gelebilen her türlü nesnenin internete erişimi ve diğer aygıtlarla iletişim halinde olması yani her nesnenin başına "akıllı" kelimesinin getirilmesi olarak tanımlanmaktadır (Muhamad ve diğ., 2017, s. 384; Bıçakcı, 2019, s. 26).

Nesnelerin İnterneti (Internet of Things) kavramı tarihte ilk olarak 1999 yılında Kevin Ashton tarafından kullanılmış olsa da (URL-6) bu kavram 1990 yılında kahve makinesinin doluluğunu uzaktan kontrol edebilmek için kurulan kameralı bir sistem fikrinden doğmuştur. Günümüze değin, nesnelerin interneti konseptli akıllı bileklikler, akıllı saatler, akıllı gözlükler, akıllı kıyafetler, akıllı spor aletleri, ev otomasyon sistemleri, akıllı arabalar gibi çeşitli ürünler hızla geliştirilmeye başlanmıştır (Bıçakcı, 2019, s. 27).

Bilgi ve iletişim teknolojilerinin kullanımı kentlerin olduğu kadar, eğitim kampüslerinin ve kullanıcılarının yaşam kalitesini de iyileştirmektedir (Villegas-Ch ve diğ., 2019, s. 4). Çeşitli sensör türlerine ve çeşitli ağlara dijital olarak bağlanmakta olan akıllı kampüsler, akıllı bir sistem aracılığıyla (IOT) kampüs içindeki insanları, aletleri, cihazları ve binaları toplu halde yönetmekte ve onlardan veri sağlamaktadır (Muhamad ve diğ., 2017, s. 385). Kampüs genelindeki heterojen kaynaklardan toplanan tüm bu veriler Nesnelerin Interneti (IOT) tarafından depolanacak, işlenecek ve analiz edilebilecektir. Bu tür süreçler ve akıllı kampüsteki uygulamalar, kampüste enerji tüketimini azaltmakta ve ayrıca güç maliyetini düşürmektedir. Bilgi ve iletişim teknolojilerinin, kurulan akıllı kampüslere entegre edilmesi ile öğrenciler aydınlanmakta ve yenilikçi fikirleriyle yeni loT'lar sağlamaktadır (Subbarao ve diğ., 2019).

\subsubsection{Bulut bilişim}

Bulut kavramı, basit network diyagramlarında interneti temsil eden bulut çiziminden yola çıkılarak üretilen bir kavramdır. Bulut bilişim ise ölçeklenebilir bir kavram olup gerçek zamanlı servis, altyapı ve uygulamaların dünyanın farklı yerlerinde bulunan sunucular üzerinden çalıştırılabilmesini ifade etmektedir. Diğer bir tanımlama ile masaüstü bilgisayar, tablet veya akıllı mobil cihazlar kullanılarak herhangi bir yazılım ve depolama birimine intiyaç duyulmaksızın internet üzerinden başka sunuculara bağlanarak hizmet alma modelidir (Kavzaoğlu ve Şahin, 2012, s. 2). Devasa ve karmaşık hesaplama ve kontrol işlemleri bulut bilişim yoluyla çözülebilmektedir (Köseoğlu ve Demirci, 2018, s. 51). 


\subsubsection{Artırılmış gerçeklik (Augmented reality)}

Eğitim, sağlık, sosyal medya, eğlence, alışveriş, acil durum ve şehircilik gibi birçok alanda kullanılmakta olan (Özcan ve diğ., 2017) "Artııılmış Gerçeklik (AR)" teknolojileri, gerçek dünyanın bilgisayar ortamında oluşturulmuş olan sanal içeriklerle zenginleştirildiği, bilgisayar tarafından oluşturulan bu içerikler ile gerçek dünya algılarımız arasında kesintisiz bir çakışmaya ve karışıma olanak tanıyan (Santos ve diğ., 2014, s. 1; Yuen ve diğ., 2011, s. 119) yeni nesil bir ara yüz olarak hizmet vermektedir (Özcan ve diğ., 2017). Mevcut kaynakları yönetmek, proaktif hizmetlerle kullanıcı deneyimini geliştirmek ve öğretim üyeleri ile öğrencilere çeşitli fırsatlar yaratmak için oluşturulmuş (Özcan ve diğ., 2017) AR teknolojisine sahip akıllı bir kampüste, öğrenciler çevrelerinde neler olup bittiğine dair daha iyi bilgi ve anlayış kazanma eğilimindedir ve bu durumun öğrenme deneyimlerini yükselttiği düşünülmektedir (Dong ve diğ., 2020, s. 2).

\subsubsection{Yapay zekâ (Al)}

Akıllı bir kampüste "Yapay Zekâ", bulut bilişim ve loT gibi cihazlara ve sistemlere zekâ özellikleri ekleyen bir tekniktir ve akıllı çözümler için platform sağlamaktadır. Yapay zekânın akılı kampüslere katkıları arasında; öğrenmeye dayalı içerikleri otomatik olarak özelleştirmesi (Sutjarittham ve diğ., 2019, s. 7595), öğrencilere bire bir olarak sanal ders alma imkânı sağlaması (Graesser, 2016, s. 125) ve gelecekteki koşulların durumunu ön görülebilir hale getirmesi yer almaktadır (Kwok, 2015, s. 2; Dong ve diğ., 2020, s. 2).

\section{Akıllı Kampüs Uygulamaları ve Bazı Örnekler}

Akıllı kampüs üzerine yapılan araştırmalar incelendiğinde akıllı kampüs kavramının, aynı konsept anlayışında fakat daha farklı bakış açıları ile tanımlandığı, örnekleri incelendiğinde ise kavramın altyapısında yer alan özelliklerin, destekleyen teknolojilerin ve uygulamaların yoğun olarak eğitim kategorisini iyileştirmek ve geliştirmek için kullanıldığı görülmektedir.

Akıllı kampüsler, özellikle bilgi ve iletişim teknolojileri olmak üzere teknolojinin etkisinden veya desteğinden ayrı tutulmamalıdır (Muhamad ve diğ., 2017, s. 385). Bu bölümde, araştırmacıların, akıllı kampüslerin özelliklerine ve gelişimlerine dair fikir sahibi olabileceğini düşündüğümüz akıllı kampüs uygulamaları ile ilgili çeşitli çalışmalar akıllı bir üniversitenin sahip olması gereken 6 bileşen; Uzaktan Eğitim (iLearning), eYönetişim (iGovernance), e- Yeşil (iGreen), e-Sağlık (iHealth), e-Sosyal (iSocial) ve eYönetim (iManagement) altında incelenmiştir (Şekil 3) (Muhamad ve diğ., 2017, s. 385; W.P. Ng ve diğ., 2010). 


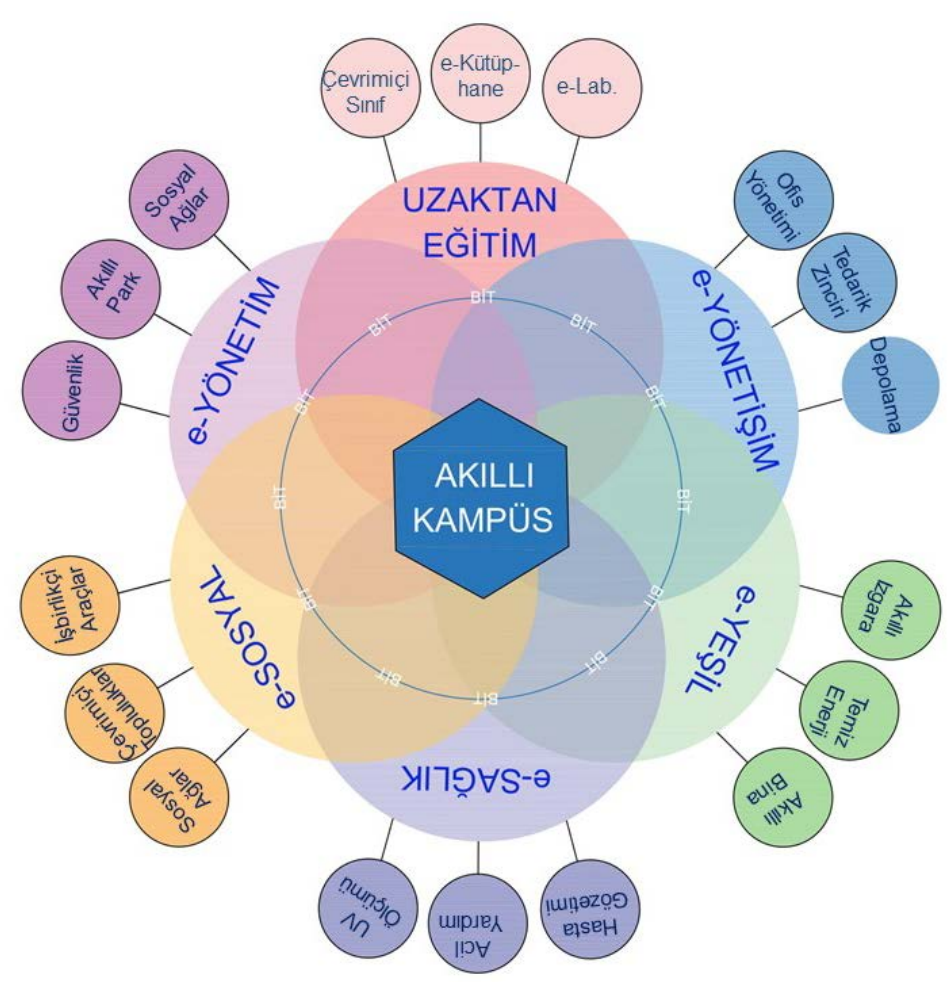

Şekil 3. Akıllı Kampüs Bileşenleri

\subsection{Uzaktan eğitim}

Üniversitelerdeki öğrenme süreçleri için fırsatlar yaratan uzaktan eğitim uygulamaları bu alanda ana aktörler olan öğretim görevlileri ve öğrenciler arasında işbirlikçi öğrenmeyi desteklerken, akademisyenlerin ve öğrencilerin mesafe, zaman ve mekân engellerine takılmadan çalışmalarını sürdürmelerini sağlamaktadır (Muhamad ve diğ., 2017, s. 386).

Uzaktan eğitimin faydaları ve eksiklikleri tartışılırken, 2019 yılında Çin'in Wuhan kentinde başlayan ve tüm dünyaya hızla yayılan korona virüs (covit-19) hastalığı nedeni ile çoğu ülkede eğitim-öğretim uzaktan (online) yapılmaya başlanmıştır (Başaran ve diğ., 2020, s. 371). Bu durum dijital ya da yazılı iletişim kaynakları aracılığı ile zaman ve mekândan kaynaklı oluşan sınırlıığı ortadan kaldırmakta olup çok çeşitli öğrenme faaliyetlerini kullanıcılara sunarak planlanmış ve tasarlanmış bir öğrenme ortamı olan uzaktan eğitim sistemi altyapısının oluşturulması gerekliliğini kanıtlamıştır (Altıparmak ve diğ., 2011, s. 320).

\subsubsection{Kırgız Türk Manas Üniversitesi Uzaktan Eğitim Merkezi}

Öğrencilerin yalnızca öğrenci işleri sistemi aracılığıyla kaydolabilecekleri çevrimiçi bir kursa katılmak için OnEd özel yazılımını geliştirmiştir. Yalnızca kayıtı öğrencilerin, kurs koordinatörlerinin ve yöneticilerin oturum açmasına izin verilen OnEd sisteminde öğrenciler kayıtlı oldukları kursların metin ve video materyallerine erişebilmektedirler. Her bölümün sonunda öğrencilerin kursun bir sonraki bölümüne erişebilmeleri için başarılı olmaları gereken bir sınav bulunmaktadır (Kyzy ve diğ., 2017, s. 654).

\subsection{2. İstanbul Üniversitesi Açık ve Uzaktan Eğitim Fakültesi}

İstanbul Üniversitesi bünyesinde açık öğretim ve uzaktan öğretim programlarının faaliyetlerini yürüten fakültedir. Google Play ve App Store'da yer alan ve iPad, iPhone ve tüm Android işletim sistemine sahip tablet ve telefonlarda kullanılabilen (URL-7) 
AUZEF Mobil uygulaması ile dünyanın her yerinden öğrencilere ders materyallerine erişimde zaman ve mekân engeline takılmadan öğretim görme ve mezun olma fırsatı sunmaktadır (URL-8).

\section{2. e-Yönetişim}

Kısa, orta ve uzun vadeli çalışma planlarını oluşturmaya, uygulamaya ve değerlendirmeye yönelik organizasyonel performansı iyileştirmeyi hedefleyen bir iş akışı sunumudur (Muhamad ve diğ., 2017, s. 387). Bu uygulamalardan bazıları: Finansal sistem, ofis sistemi, akıllı tedarik zinciri (depolama koşullarının izlenmesi ve ürün takibi) kontrolüdür (URL-9).

\section{3. e-Yeşil}

Genel olarak "yeşil kampüs" hedefleri örnek alınarak; küresel ısınmayı ve üniversite ortamındaki karbon kirliliği derecesinin artmasına neden olan etkileri önlemeye yönelik uygulamalara yer verilmesidir (Muhamad ve diğ., 2017, s. 387). Akıllı bina sistemleri (iç mekân hava kalitesi kontrolü,), akıllı ulaşım, akıllı enerji yönetim sistemleri (akıllı ızgara (smart grid), akıllı aydınlatma, akıllı musluklar, uzaktan kumandalı cihazlar, güneş enerjili elektrik santrali vb.), akıllı atık ve su yönetimi, kimyasal kaçak tespiti, akıllı tarım uygulamaları buna örnek verilebilmektedir (Lazaroiu ve diğ., 201, s. 2).

\subsubsection{Washington Üniversitesi Akıllı Şebeke Projesi (UW Smart Grid Project)}

Kampüs içerisinde enerji tasarrufunu artırmak ve güç sistemlerini daha güvenilir hale getirmek amacı ile kampüste yer alan binalarda enerji kullanımını ölçen ve bu ölçümleri analiz ederek proaktif müdahalesine imkân tanıyan bir bilgisayar yazılımına aktaran 200'den fazla enerji sayacı kurulmuştur. Burada amaç enerji israfını azaltmanın yanı sıra kampüste uzun vadeli karbon azaltma hedeflerine ulaşmada etkin rol oynadığı düşünülen, yurtlarda yaşayan öğrencilerin enerji kullanım alışkanlıklarını belirleyerek nasıl bir strateji uygulanması gerektiğine yönelik kararlar alabilmektir. Proje aynı zamanda kullanıcıların enerji kullanımları, enerji kullanımlarının çevresel etkileri ve maliyetleri gibi konularda detaylı bilgi edinmeye nasıl tepki verdiklerini test etmeyi amaçlamaktadır (URL-10).

\subsubsection{Michigan Üniversitesi Sürücüsüz Araç Test Sahası Uygulaması}

Sürücüsüz, tam otomatik veya otonom olarak da adlandırılan kendi kendine giden araçlarla yapılan yolculuk denemelerinin çoğu kaza ile sonuçlanmaktadır. Büyük çoğunluğu insan kaynaklı gerçekleşen bu kazaları ve test sırasında ortaya çıkan bazı sorunları çözmek için caddelerdeki kaotik deneyimi kontrollü bir ortam oluşturarak ideal bir test sahası yaratmayı hedefleyen Michigan Üniversitesi, Mcity adını verdiği sahte bir kasaba kurmuştur. Araştırma projesinde, Fransız Navya firması tarafından üretilmiş olan iki adet tam otomatik, 11 koltuklu, tamamen elektrikli, dış (sürücüler, bisikletliler ve yayaların tepki ve davranışlarını gözlemlemek için) ve iç (yolcuların tepkilerini gözlemlemek için) kameralara sahip servis aracı kullanılmıştır. Mcity, ayrıca yolcu sayısını ve kullanıcı grubunu da belirleyerek araştırmacıların zaman içinde daha güvenli araçların nasıl tasarlanacağını ve daha verimli bir şekilde nasıl çalıştırılacağını anlamalarına rehberlik etmesi amacı ile kullanıcılara yolculuk deneyimleri hakkında anket yapmaktadır (URL-11).

\subsubsection{Portland Üniversitesi Dijital Şehir Test Merkezi Akıllı Ağaç Projesi}

Proje, küresel ısınmanın sosyal ve çevresel etkilerini azaltmada önemli bir rol oynayan kentsel bitki (ağaç) örtüsünün sağlığını izlemek ve kentsel ortamlarda ağaçların neler yaşadığını daha iyi anlamak için bir dizi teknolojiden yararlanmaktadır. Araştırmacılar 
sensör, uydu ve drone aracılığı ile bitkinin yaşam kalitesini etkileyen sıcaklık, hava, nem, kuraklık stresi gibi koşullar hakkında uzaktan veri toplamakta ve tüm bu verileri akıllı telefon aracılığı ile erişilebilen bulut tabanlı bir depolama alanında toplamaktadır (URL-12).

\subsection{4. İstanbul Teknik Üniversitesi Ayazağa Yerleşkesi bisiklet paylaşım sistemi}

Kampüs içerisinde minimum karbon salınımı hedefleyen ITÜ Ayazağa Kampüsü, bisikletli hayat anlayışını benimsemekte ve bunun için toplamda 6 kilometrelik bir alanı kaplaması planlanan bisiklet ve yaya yolu projesi tasarlamaktadır. 180 adet (10'u pedal destekli-elektrikli) bisiklet kurulan akıllı sistemle paylaşımlı hale dönüştürülmüştür. Paylaşımlı bisikletler kampüsteki yaya ve araç dolaşım döngüsü dikkate alınarak konumlandırılmış, bordo renk ile boyalı istasyon alanlarından Bizero uygulaması ile kiralanıp, herhangi bir paylaşımlı bisiklet istasyon alanına bırakılabilmektedirler (URL13; URL-14).

\subsubsection{Hamdan Bin Mohammed Akıllı Üniversitesi Enerji Optimizasyonu Projesi}

Enerji tüketimini ve $\mathrm{CO}_{2}$ emisyonunu azaltmayı buna bağlı olarak kampüsteki işletme maliyetlerini düşürmeyi hedefleyen üniversite, Honeywell Forge'un makine öğrenimi ve otonom kontrol teknolojilerinin bir kombinasyonu aracılığı ile en yüksek kapasitede çalışıp çalışmadığını belirlemek için her 15 dakikada bir binanın HVAC (Heating, Ventilating and Air Conditioning) sistemi için dâhili ayar noktalarını değerlendiren kapalı döngü bir çözümün pilot uygulamasını hayata geçirmiştir. Sistem, zaman, hava durumu, doluluk seviyeleri gibi faktörleri analiz ederek, enerji tüketimini azaltmak için her 24 saatlik dönemde, gerçek zamanlı verilere dayalı ayarlamaları otomatikleştirerek kampüs genelinde enerji tüketiminde yüzde 10 azalma sağlamaktadır (URL-15).

\section{4. e-Sağlık}

Ana hedefi kampüs nüfusunun genel sağlık durumunu izlemek ve sürdürmek olan eSağlık sistemi hizmetleri; kampüs sakinlerine her zaman ve her yerde sağlık hizmetleri sunarken elde edilen bulguların izlenmesi ve kaydedilmesini amaçlamaktadır (Muhamad ve diğ., 2017, s. 387). Düşme algılama tespiti ve acil yardım (özellikle engelli ve yaşlı bireyler için), UV güneş ışınlarının ölçümü, uzaktan hasta gözetimi esağlık hizmetlerine örnek verilebilmektedir (URL-9).

\section{5. e-Sosyal}

Mevcut sosyal ağ teknolojilerinin artan kullanımları dikkate alındığında üniversitelerde sosyal sürecin bir parçası haline gelmeleri de normal karşılanmalıdır. e-Sosyal etki alanını karşılamak için akıllı kampüs sistemlerinde; öğrenci profillerinin belirlenebilmesi ve öğrencilerin ilgi alanlarına göre gruplar oluşturabilmesi, sosyal ağlarda depolanan verilere göre duyarlılık analizi yapılabilmesi, hizmetlerin öğrencilerin ilgi alanlarına göre belirlenmesi ve doğru zamanda doğru yerde geliştirmesi gerekmektedir. Günümüzde Facebook, Instagram ve Twitter gibi Sosyal Ağ Siteleri (SNS) üniversite öğrencilerinin iletişim kurmalarını ve topluluklarla bir araya gelmelerini sağlayan bir araç haline gelmiştir. Kablosuz iletişim ve akıllı telefonların gelişmesi sosyal ağların mobil hale gelmesine neden olduğu için mobil sosyal ağlar ortaya çıkmıştır (Yu ve diğ., 2011, s. 163). Hali hazırda kampüs içerisindeki insanları ve toplulukları bir araya getirmek için kullanılan pek çok uygulama bulunmaktadır. $\mathrm{Bu}$ uygulamaların yaygınlaşması kullanıcılarına zaman ve mekân engeline takılmadan sosyalleşme imkânı tanımaktadır. 


\subsubsection{Yonsei Üniversitesi etkinlik paylaşım platformu}

Bilgi ve iletişim teknolojilerinden faydalanılarak oluşturulmuş OCX (Açık Kampüs Deneyimi) adı verilen bir konsept aracılığıyla kampüste oluşturulan tüm bilgilerin yönetilmesi ve paylaşılması amaçlanmaktadır. Sistem aracılığıyla tüm kültürel, sanatsal, akademik faaliyetler öğrencilere mobil takvim ile duyurulmakta ve çevrimiçi video klipler sayesinde öğrenciler bunlara erişebilmektedir. Öğrenciler ve akademisyenler mobil kimlik kartlarını kullanarak kütüphanelerdeki verilere erişebilmekte, ayrıca servis otobüsünün kampüs içindeki yerini ve kafeteryaların öğrencilerle dolu olup olmadığını kontrol edebilmektedirler (URL-16).

\section{6. e-Yönetim}

Akıllı yönetim üniversitede bulunan tesisler ve altyapının yanı sıra kampüs içindeki insanları (personel, öğretim görevlisi, öğrenciler, misafirler) içermektedir. Bu sistem, yüz tanıma teknolojisinin kullanılması gibi yöntemlerle kampüs içerisinde suç işlenmesini önlemeyi, kullanıcı dağııımını belirleyebilmek için hareket takibini, park izni, bisiklet kullanımı gibi işlemler için akıllı kartları ve bir öğretme ve öğrenme etkinliğine katııımın kaydedilmesi gibi işlemleri desteklemektedir (Muhamad ve diğ., 2017, s. 387).

\subsubsection{Leiria Teknik Okulu akıllı kampüs otoparkı}

Kampüsteki otoparkların verimli yönetimi için geliştirilmiş olan bu sistemde ana amaç, sürücülere kampüsteki park yerlerinin mevcudiyeti hakkında rehberlik etmek ve otoparklardaki sensörlerden elde edilen güncel bilgileri sunmaktır. Çalışma, park sensörleri tarafından üretilen verileri eş zamanlı olarak toplamayı, hesaplamayı ve sürdürmeyi amaçlayan çeşitli teknolojilerin ve uygulamaların entegrasyonuna dayanmaktadır. Kullanıcılar, REST web hizmeti ile iletişim kuran bir Android uygulaması ile bu verilere erişebilmektedir (Vieria ve diğ., 2019, s. 3).

\subsubsection{Arizona Eyalet Üniversitesi Akıllı Stadyum Projesi}

300 milyon doların üzerinde bir harcama yapılarak revize edilmiş olan Arizona Eyalet Üniversitesi'nin futbol stadyumunda taraftar katıımı, kalabalık yönetimi, etkinlik lojistiği, stadyum yönetimi, saha bakımı ve çevresel izleme sorunlarını ele almak için video kameralar ve mikrofonlar dâhil olmak üzere farklı yerlere konumlandırılmış sensörler kullanılmıştır (URL-17).

\section{Sonuç ve Öneriler}

İnsanlığın başarıya ulaşması kentlerimizin ve üniversitelerimizin başarıya ulaşmasına bağılır. Özellikle gençler için bir cazibe merkezi haline gelen üniversitelerin kullanıcılarının beklentilerini karşılayabilmeleri için içinde bulunduğumuz çağın getirdiği yenilikleri özümsemesi ve gerekirse üniversite kampüslerinin yeniden düzenlenmesi gerektiği düşünülmektedir.

Çalışmamızda incelenen örnekler göstermektedir ki üniversiteler, her türlü nesnenin internete erişiminin sağlanması ve diğer aygıtlarla iletişim halinde olması teknolojisine dayanan Nesnelerin interneti, Bulut Bilişim, Artırımış Gerçeklik ve Yapay Zekâ sayesinde hem kendi kendilerini sürdürebilecek hem de daha sağlıklı ve tüm sakinleri için daha güvenli bir yer haline gelebilecektir. Üniversite kampüslerinin biz insanlar ve teknolojik gelişmeler arasında gittikçe artan bağlantılar ve dijitalleşme için iyi bir test alanı niteliğinde olması nedeni ile akıllı kampüs uygulamalarının desteklenmesi, üniversiteleri bu fırsatları yakalamak ve gerçek bir dönüşüm sağlamak için teşvik etmektedir. 
Kampüsler barındırdıkları genç ve istekli beyinler dikkate alındığında en yeni fikir ve uygulamaların test edilmesinde etkin bir işlev görmelidir. Bugünün üniversiteleri; hızlı nüfus artışılla ve artan taleple başa çıkabilecek bir donanıma sahip olmalı, mevcut alanları etkili bir şekilde kullanmanın yanı sıra hizmetleri etkili ve verimli bir şekilde sunmalı ve kampüs standartlarını iyileştirebilmek için modern teknolojiden faydalanmalıdır. Bununla birlikte, üniversitelerde teknolojik inovasyon sayesinde yeni bir dinamizmin geliştirilmesi gerektiği de düşünülmektedir. Üniversitelerin donanım, veri depolama, ağ ve platform gerektiren nesnelerin internetinin faydalarından yararlanılabilmesi için dijitalleşme önemli bir rol oynamaktadır. Mevcut gereksinimler düşünülerek yeniden inşa edilen veya sıfırdan kurulan üniversite kampüsleri kullanıcılarına üst düzey hizmet sunmak ve akademik kaliteyi yükseltmek için dijital teknolojilerden yararlanarak biçimlendirilmelidir.

Değişen çağın getirdiği yeniliklere ve yeni nesil bireylerin beklentilerine ek olarak içinde bulunduğumuz yeni tip korona virüs (Covid-19) pandemi süreci de, özellikle uzaktan eğitim teknolojilerine sahip akıllı kampüs temellerinin ivedilikle atılması gerektiğini, mevcut zorluklar ve aksaklıklar göz önünde bulundurulduğunda, geleneksel eğitim sisteminin artık eskisi kadar başarılı olamayacağını bizlere göstermiştir. Bu doğrultuda üniversitelerde eğitim sistemini daha erişilebilir hale getirmek ve engellerin ortasında büyümesini ve ilerlemesini desteklemek için nesnelerin interneti, bulut bilişim, artırılmış gerçeklik ve yapay zekâ teknolojilerinden en üst seviyede yararlanılmalıdır.

Çok yönlü hedeflere sahip; altyapı ve çevreye ilişkin sorunlara çözüm sağlayan, bilişim, bilim ve teknoloji temeline dayanan, bilgi ve iletişim teknolojilerinden yararlanan, kaynaklarını etkin ve verimli kullanan akıllı kampüs projelerinin hayata geçirilmesi, kampüsleri yaşam kalitesini arttırmak ve sürdürülebilirlik düzeyini iyileştirmek gibi nihai hedeflerine yakınlaştıracaktır.

Akıllı kampüs teknolojilerine ve akıllı öğrenmeyi teşvik eden diğer bütün uygulamalara dair deneyimlerin ve tecrübelerin incelenerek paydaşlarla paylaşılması gelecekte yapılacak olan çalışmalara ışık tutacaktır. Çalışmamız kapsamında gerçekleştirilen araştırmalar ve incelenen örnekler sonucunda Türkiye'de yer alan akıllı kampüs uygulamalarının geniş çapta olmadığı, çalışmaların yalnızca teknolojik gelişmelere odaklanmış olduğu ve fiziksel mekânlara yansıtılmasının sınırlı kaldığı sonucuna ulaşılmıştır. Dünya'dan başarılı örnekler dikkate alındığında; Türkiye'de akıllı kampüs olgusunun geçerlilik kazanabilmesi için daha bütüncül çalışmaların hedeflenmesi; üniversitelerin öğrenciler, akademisyenler ve yerel yönetimler ile işbirliği içerisinde olması ve kampüslere yönelik alınan kararların ekonomik, sosyal ve ekolojik denge gözetilerek hayata geçirilmesi gerekmektedir.

\section{Kaynaklar}

Akbaş, İsmet, "Akıllı Kentler: AB ve Türkiye Analizi”, Sosyal Bilimler Dergisi, 2018, 5(16) s.139-165

Albino, Vito, Berarti, Umberto, Dangelico, Rosa Maria, "Smart Cities: Definitions, Dimensions, and Performance", Journal of Urban Technology, 2015, 22(1) s.17231738.

Altıparmak, Mahinur, Kurt, İnci Dürdane, Kapıdere, Metin, "E-Öğrenme ve Uzaktan Eğitimde Açık Kaynak Kodlu Öğrenme Yönetim Sistemleri”, Akademik Bilişim'11 - XIII. Akademik Bilişim Konferansı Bildirileri, Malatya 2011, s. 319- 327. 
Başaran, Mehmet, Doğan, Elif, Karaoğlu, Esra, Şahin Ecem, "Koronavirüs (Covıd-19) Pandemi Sürecinin Getirisi Olan Uzaktan Eğitimin Etkililiği Üzerine Bir Çalışma", Academia Eğitim Araştırmaları Dergisi, 2020, 5(2):368-397.

Bıçakçı, Saliha Nur, "Internet of Things”, Takvim-i Vekayi, 2019, 7(1) s.24-36.

Bilici, Zekeriya, Babahanoğlu Veysel, "Akıllı Kent Uygulamaları ve Konya Örneği”, Akademik Yaklaşımlar Dergisi, 2018, 9(2), s.124-139.

Bria, Francessa, New Governance Models Towards an Open Internet Ecosystem for Smart Connected European Cities and Regions. In Open Innovation, Directorategeneral For The Information Society and Media, European Commission, 2012.

Cohen, Boyd, "Blockchain Cities and the Smart Cities Wheel", Erişim: https://medium.com/iomob/blockchain-cities-and-the-smart-cities-wheel-9f65c2f32c36 Designing Smart Mobility Services", Government Information Quarterly, 2018, 35(1).

Dameri, Reneta, Cocchia, A., "Smart City and Digital City: Twenty Years of Terminology Evolution”, X Conf. Ital. Chapter AIS, ITAIS 2013, s.1-8.

Dong, Zhao Yang, Zhang, Yuchen, Yip, Chritistine, Swift, Sharon, Beswick, Kim, "Smart Campus: Definition, Framework, Technologies and Services", IET Smart Cities, 2020, 2(1).

Du, Shouyan, Meng, Fansheng, Gao, Baozhong, "Research on the Application System of Smart Campus in the Context of Smart City", 8th International Conference on Information Technology in Medicine and Education (ITME), 2016.

European Parliament, Mapping Smart Cities in the EU, 2014.

Fortes, Sergio, Santoyo-Ramón, Jose Antonio, Campos, David Palacios, Baena, Eduardo, Mora-García, Rocío, Medina, Miguel, Mora, Patricia, Barco, Raquel, "The Campus as a Smart City: University of Málaga Environmental, Learning, and Research Approaches", Sensors, 2019, 19(6):1349.

Gil-Garcia, J. Ramon, Pardo, Theresa A., Nam, Taewoo, "What Makes a City Smart? Identifying Core Components and Proposing an Integrative and Comprehensive Conceptualization", Information Polity, 2015, 20(1):61-87.

Graesser, Arthur C., "Conversations with Auto Tutor Help Students Learn", Int. J. Artif. Intell. Educ., 2016, 26(1) s. 124-132.

Gürsoy, Oğuzhan, Akıllı Kent Yaklaşımı ve Türkiye'deki Büyükşehirler için Uygulama İmkânları, Hacettepe Üniversitesi Sosyal Bilimler Enstitüsü Yüksek Lisans Tezi, Ankara 2019.

Gürsoy, Oğuzhan, Ömürgönülşelen, Uğur, "Akıllı Kent Bileşeni Olarak "Akıllı Vatandaş" Bağlamında Bir Test Sahası Olarak Üniversite Kampüsleri”, Uluslararası Yönetim Akademisi Dergisi, 2019. 2(1):19-28.

Harrison, Colin, Donnelly, Ian Abbott, "A Theory of Smart Cities", Proceedings of the 55th Annual Meeting of the ISSS-2011, s.17-22. 
Herzberg, Casper, Akıllı Şehirler Dijital Ülkeler, Optimis Yayım Dağıtım San. ve Tic. Ltd. Şti. Editör: Zülfü Dicleli. İstanbul 2017.

Işık, Şevket, “Türkiye'de Kentleşme ve Kentleşme Modelleri”, Ege Coğrafya Dergisi 14, 2005 İzmir, s. 57-71.

Jenal, Ruzzakiah, Suwadi, Nur A., Mahayuddin, Zainal R., Arshad, Haslina, Adiono, Trio, "Implementation of Digital Campus in Fostering Campus Sustainebility" AIP Conference Proceedings, 2016(1).

Kavzaoğlu, Taşkın, Şahin, Emrehan K., "Bulut Bilişim Teknolojisi ve Bulut Cbs Uygulamaları” IV. Uzaktan Algılama ve Coğrafi Bilgi Sistemleri Sempozyumu 2012.

Keleş, Ruşen, Kent Bilimleri Sözlüğü. Ankara: İmge Kitabevi,1998.

Kitchin, Rob, "Making Sense of Smart Cities: addressing present shortcomings" Cambridge Journal of Regions, Economy and Society, 2015, (8): 131-136

Köseoğlu, Özer, Demirci, Yılmaz, "Akıllı Şehirler ve Yerel Sorunların Çözümünde Yenilikçi Teknolojilerin Kullanımı" Uluslararası Politik Araştırmalar Dergisi, 2018, 4(2): 40-57.

Kwok, Lam For, "A Vision for the Development of I-Campus", Smart Learning Environments, 2015, 2(2) s. 1-12.

Kyzy, Zuhumagul Nurakun, Begimkulov, Chyngyz, Ismailova Rita, Dündar Hakan, "Evaluation of Distance Education Applications in the Kyrgyz Republic Universities", International Online Journal of Educational Sciences, 2017, 9(3):653 - 662.

Lazaroiu, George C., Dumbrava, Virgil, Costoiu, Mihnea, Teliceanu, Mihaela, Roscia, M., "Smart Campus-an Energy Integrated Approach", International Conference on Renewable Energy Research and Applications (ICRERA) 2015.

Liu, Dejian, Huang, Ronghuai, Wosinski, Marek, "Smart Learning in Smart Cities" Springer, 2017, s. 1-232.

Lombardi, Patrizia, Giordano, Silvia, Farouh, Hend, Yousef, Wael, "Modelling the Smart City Performance", Inno-vation: The European Journal of Social Science Research 2012, 25: (2) s. $137-149$.

Mirghaemi, Sayed Amir, Türkiye'de Akıllı Kent Sistemleri Üzerine Bir İnceleme, T.C. İstanbul Aydın Üniversitesi Fen Bilimleri Enstitüsü Mimarlık Ana Bilim Dalı, Yüksek Lisans Tezi. İstanbul 2019.

Muhamad, Wardani, Kurniawan, Novianto Budi, Suhardi, Suhardi, Yazid, Setiadi, "Smart Campus Features, Technologies and Applications: A Systematic Literature Review", International Conference on Information Technology Systems and Innovation (ICITSI), Bandung 2017.

Nam, Theresa, Pardo, Taewoo A., "Conceptualizing Smart City with Dimensions of Technology, People, and Institutions" Proceedings of the 12th Annual International Conference on Digital Government Research, USA 2011. 
Örselli, Erhan, Akbay, Can, "Teknoloji ve Kent Yaşamında Dönüşüm: Akıllı Kentler”, Uluslararası Yönetim Akademisi Dergisi. 2019, 2(1) s.228-241.

Örselli, Erhan, Bilici, Zekeriya, Babahanoğlu, Veysel, "Akıllı Vatandaş, Akıllı Kentler ve Türkiye", International Congress on Politic, Economic and Social Studies, Proceedings Vol. 1: Political Studies, 2018, s.1-14.

Özcan, Uğur, Arslan, Aslıhan, İlkyaz, Menekşe, Karaarslan Enis, "An Augmented Reality Application for Smart Campus Urbanization: MSKU Campus Prototype", 5th International Istanbul Smart Grid and Cities Congress and Fair (ICSG) 2017.

Pagliaro, Francesca, Mattoni, Benedetta, Gugliermetti, F., Bisegna Fabio, Azzaro, Bartolomeo, Tomei Francesco, Catucci, Stefano, "A Roadmap Toward the Development of Sapienza Smart Campus", 16th International Conference on Environment and Electrical Engineering (EEEIC) 2016.

Sadioğlu, Uğur, Dinç, Betül, Akıllı Kent, Akıllı İnsan ve Yaşam Boyu Öğrenme İlişkisi Üzerine Bir Bakış. Yeşil Kampüs: Kapsam Uygulama Yönetim, Editör: Prof. Dr. M. Kemal Öktem, Doç. A. Selin Mutdoğan, Hacettepe Üniversitesi , 2020, ss. 224.

Santos, Marc Ericson, Chen, Angie, Taketomi, Takafumi, Yamamoto, Goshiro, Miyazaki, Jun, Kato, Hirozaku, "Augmented Reality Learning Experiences: Survey of Prototype Design and Evaluation", IEEE Trans. Learn. Technol., 2014, 7(1):38-56.

Subbarao, Voore, Srinivas, K., Pavithr, R. S., "A Survey on Internet of Things Based Smart, Digital Green And Intelligent Campus", 4th International Conference on Internet of Things: Smart Innovation and Usages (IOT-SIU), 2019.

Susanti, Retno, Soetomoa, Sugiono, Buchoria, Imam, Brotosunaryoa, P. M., "Smart Growth, Smart City and Density: in Search of The Appropriate Indicator for Residential Density in Indonesia", Social and Behavioral Sciences, 2016, Vol:227, s. $194-201$.

Sutjarittham T., Gharakheili H. H., Kanhere, S. S., Sivaraman, V., "Realizing a Smart University Campus: Vision, Architecture, and Implementation", IEEE International Conference on Advanced Networks and Telecommunications Systems (ANTS), India 2018.

Sutjarittham, Thanchanok, Gharakheili, Hassan Habibi, Kanhere, Salil S., Sivaraman, Vijay, "Experiences with lot and Al in a Smart Campus for Optimizing Classroom Usage", IEEE Internet Things J., 2019, (5) s. 7595-7607.

Torres-Sospedra Joaquin, Avariento, Joan Pere, Rambla, David, Montoliu, Raul, Casteleyn, Sven, Benedito-Bordonau, Mauri, Gould, Michael, Huerta, Joaquin, "Enhancing Integrated Indoor/Outdoor Mobility in a Smart Campus", International Journal of Geographical Information Science, 2015, 29(11), s.1955-1968.

Vasileva, Roza, Rodrigues, Lucelia, Hughes, Nancy, Greenhalgh, Chris, Goulden, Murray, Tennison, Jeni, "What Smart Campuses Can Teach Us about Smart Cities: User Experiences and Open Data, Information", Switzerland 2018, 9(10):251. 
Vieria, Amanda, Rosa, Iolanda, Santos, Ivo, Paulo, Tiago, Costa, Nuno, Maximiano, Marisa, Reis, Catarina, "Smart Campus Parking - Parking Made Easy, Computational Science", 19th International Conference, Proceedings, Part V, Portugal 2019.

Villegas-Ch, William, Palacios-Pacheco, Xavier, Luján-Mora, Sergio, "Application of a Smart City Model to a Traditional University Campus with a Big Data Architecture: A Sustainable Smart Campus", Sustainability, 2019, 11(10):285.

W.P.Ng, Jason, Azarmi, Nader, Leida, Marcello, Saffre, Fabrice, Afzal, Ali, Yoo, Paul, The Intelligent Campus (iCampus): End-to-End Learning Lifecycle of a Knowledge Ecosystem, ntelligent Environments (IE), Sixth International Conference, 2010.

Yu, Zhiwen, Liang, Yunji, Xu, Bukan, Yang, Yue, Guo, Bin, "Towards a Smart Campus with Mobile Social Networking", International Conference on Internet of Things and 4th International Conference on Cyber, Physical and Social Computing, 2011.

Yuen, Steve C.-Y., Yaoyuneyong, Gallayanee, Johnson, Erik, "Augmented Reality: An Overview and Five Directions For AR in Education", Journal of Educational Technology Development and Exchange, 2011,4(1) s.119-140.

URL-1: 2018 Revision of World Urbanization Prospects.

https://www.un.org/development/desa/publications/2018-revision-of-world-urbanizationprospects.html\#: :text=Today\%2C\%2055\%25\%20of\%20the\%20world's, increase $\% 20 \mathrm{t}$ o\%2068\%25\%20by\%202050.\&text=The $\% 20$ urban\%20population $\% 20$ of $\% 20$ the,to\%20 4.2\%20billion\%20in\%202018

URL-2: T.C. Çevre ve Şehircilik Bakanlığı. 2020-2023 Ulusal Akıllı Şehirler Stratejisi ve Eylem Planı. https://www.akillisehirler.gov.tr/wp-content/uploads/EylemPlani.pdf (Erişim Tarihi: 6.10.2020)

URL-3: Akıllı Şehir Nedir? https://www.akillisehirler.gov.tr/akilli-sehir-nedir/ (Erişim Tarihi: 09.10.2020)

URL-4: Akıllı Şehir. TÜBITAK. BILGEM YTE.

https://yte.bilgem.tubitak.gov.tr/sites/images/bilgem/tubitak bilgem yte akillisehirlerbro sur.pdf (Erişim Tarihi: 7.10.2020)

URL-5: Smart Campuses: The next-generation campus.

https://www2.deloitte.com/us/en/pages/consulting/solutions/next-generation-smartcampus.html (Erişim Tarihi: 20.10.2020)

URL-6: Internet Of Things (Nesnelerin İnterneti) Nedir?

http://www.teknolo.com/internet-things-nesnelerin-interneti-nedir/ (Erişim Tarihi: 21.10.2020)

URL-7: AUZEF Mobil. https://auzef.istanbul.edu.tr/tr/content/auzef-mobil/auzef-mobilitaniyalim (Erişim Tarihi: 12.12.2020)

URL-8: İstanbul Üniversitesi Açık ve Uzaktan Eğitim Fakültesi.

https://auzef.istanbul.edu.tr/tr/content/fakultemiz/hakkinda (Erişim Tarihi: 12.12.2020) 
URL-9: 50 Sensor Applications for a Smarter World.

https://www.libelium.com/libeliumworld/top-50-iot-sensor-applications-ranking/ (Erişim Tarihi: 02.11.2020)

URL-10: UW Smart Grid Project. University of Washington (2010-2015)

https://green.uw.edu/promote/snapshots/uw-smart-grid-project (Erişim Tarihi:

02.11.2020)

URL-11: Mcity Driverless Shuttle: What We Learned About Consumer Acceptance of Automated Vehicles. https://mcity.umich.edu/wp-content/uploads/2020/10/mcitydriverless-shuttle-whitepaper.pdf (Erişim Tarihi: 03.11.2020)

URL-12: Smart Trees Hold Clımate Clues. https://www.pdx.edu/news/smart-trees-holdclimate-clues (Erişim Tarihi: 04.11.2020)

URL-13: iTÜ'de Paylaşımlı Bisiklet Devri http://www.itu.edu.tr/ituhakkinda/haberler/2018/04/20/i-tu-de-paylasimli-bisiklet-devri (Erişim Tarihi: 09.11.2020)

URL-14: Bisiklet ve Yaya Öncelikli ITÜ. https://yesilkampus.itu.edu.tr/yesilkampus/bisiklet-ve-yaya-oncelikli-itu (Erişim Tarihi: 09.11.2020)

URL-15: A Smart University Gets Smarter with Energy Optimization. https://www.honeywell.com/en-us/honeywell-forge/smart-university-gets-smarter-withenergy-optimization (Erişim Tarihi: 09.11.2020)

URL-16: World's Best Smart Campus! The Future of The World Begins at Yonsei. https://www.yonsei.ac.kr/en sc/campus/scampus.jsp. (Erişim Tarihi: 10.10.2020)

URL-17: The Future of Higher Education: Smart Campuses. https://spaces4learning.com/articles/2019/03/01/smart-campuses.aspx (Erişim Tarihi: 04.11.2020) 